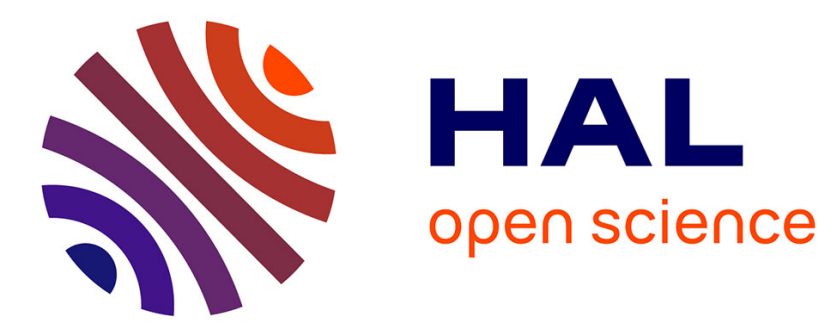

\title{
Sensitivity of a 5-phase Brushless DC machine to the 7 th harmonic of the back-electromotive force
}

\author{
Eric Semail, Xavier Kestelyn, Alain Bouscayrol
}

\section{To cite this version:}

Eric Semail, Xavier Kestelyn, Alain Bouscayrol. Sensitivity of a 5-phase Brushless DC machine to the 7th harmonic of the back-electromotive force. Power Electronics Specialists Conference, 2004. PESC 04. 2004 IEEE 35th Annual, Jun 2004, AACHEN, Germany. pp.4564 - 4570, 10.1109/PESC.2004.1354807 . hal-01314306

\section{HAL Id: hal-01314306 https://hal.science/hal-01314306}

Submitted on 11 May 2016

HAL is a multi-disciplinary open access archive for the deposit and dissemination of scientific research documents, whether they are published or not. The documents may come from teaching and research institutions in France or abroad, or from public or private research centers.
L'archive ouverte pluridisciplinaire HAL, est destinée au dépôt et à la diffusion de documents scientifiques de niveau recherche, publiés ou non, émanant des établissements d'enseignement et de recherche français ou étrangers, des laboratoires publics ou privés. 


\title{
Sensitivity of a 5-phase Brushless DC machine to the $7^{\text {th }}$ harmonic of the back-electromotive force
}

\author{
E. Semail, X. Kestelyn and A. Bouscayrol \\ L2EP, Laboratoire d'Electrotechnique et d' Electronique de Puissance de Lille \\ ENSAM Lille 8 bd Louis XIV F-59046 LILLE, France \\ e-mail: eric.semail@lille.ensam.fr \\ http://www.univ-lille1.fr/12ep/
}

\begin{abstract}
This paper presents a vector control of a 5phase drive composed of a 5-leg Pulse Width Modulation (PWM) Voltage Source Inverter (VSI) supplying a permanent-magnet Brushless DC (BLDC) machine with trapezoidal waveform of the back-electromotive force (EMF). To achieve this control a Multi-machine Multiconverter model is used: the 5-phase machine is transformed into a set of two 2-phase fictitious machines which are each one controlled in a $(d, q)$ frame as 3-phase machines with sine waveform back-EMF. In comparison with the 3-phase BLDC drives, the 5-phase ones present one particularity: a high sensitivity to the $7^{\text {th }}$ harmonic of backEMF. Experimental results show that the $7^{\text {th }}$ harmonic of back-EMF, which represents only $5 \%$ of RMS back-EMF, induces high amplitude parasitic currents $(29 \%$ percent of RMS current). The model allows to explain the origin of this sensitivity and how to modify simply the control algorithm. Experimental improvements of the drive are presented.
\end{abstract}

Index Terms-brushless, multiphase, 5-phase, drive control.

\section{INTRODUCTION}

Multi-phase drive systems have several advantages over conventional 3-phase ones [1]-[2] such as higher reliability and reduction of torque ripples. Multi-phase machines have been initially supplied from Pulse Amplitude Modulation Current Stiff Inverter (PAM CSI) [3]-[5]. In this case, a machine with $q$ 3-phase stars can be considered as the association of $q$ 3-phase machines mechanically coupled on the same shaft. Each 3-phase fictitious machine is associated with one of the $q$ stars. This decomposition is possible in spite of the magnetic couplings between the stars, because of one property of the PAM CSI drive: when there is commutation of a current in a star, the currents in the other stars have constant values. The mutual inductances between stars have no impact and the stars can be then considered as magnetically independent.

With Digital Signal Processor, it is now possible to use PWM VSI in multi-phase drives [6]-[8].

If vector controls of 3-phase BLDC machines are well known [9], it is not the case for multi-phase ones, particularly if the waveform of back-EMF is trapezoidal. PWM-VSI requires a much more precise modeling than PAM CSI: it is no more obvious to decompose the multiphase machine into a set of 3-phase machines.

For six-phase induction machines, [10] has proposed a multiple reference frame analysis based on an orthogonal transformation. The natural frame $(\mathrm{a}, \mathrm{b}, \mathrm{c}, \mathrm{d}, \mathrm{e}, \mathrm{f})$ of the 6phase machine is transformed into a set of three independent frames $\left(\mathrm{o}_{1}, \mathrm{o}_{2}\right),(\mathrm{d}, \mathrm{q})$ and $\left(\mathrm{z}_{1}, \mathrm{z}_{2}\right)$ where dynamic equations of the machine are totally decoupled. When currents are sinusoidal, the planes $\left(\mathrm{o}_{1}, \mathrm{o}_{2}\right)$ and $\left(\mathrm{z}_{1}, \mathrm{z}_{2}\right)$ do not participate to electromechanical conversion. Recently, using the same transformation, [11] shows the possibility to improve torque density with the injection of a third harmonic current, harmonic which is relative to the plane $\left(\mathrm{o}_{1}, \mathrm{o}_{2}\right)$. For 5-phase induction machines, similar transformations have been used to achieve a DTC control [7] or to drive with only a 5-leg VSI supply two series connected motors [12]. Multi-phase BLDC machines have been less studied [13]-[15] than multi-phase induction machines. In [13], torque density has been increased with $3^{\text {rd }}$ harmonic current injection in a 5-phase synchronous reluctance motor drive.

In this paper, a 5-phase BLCD supplied by a 5-leg PWMVSI is studied. Using a Multi-machine Multi-converter description, this drive is broken down into two fictitious machines which can be controlled independently. This specific modeling shows that the $7^{\text {th }}$ harmonic of the EMF leads to important parasitic currents. Controls strategies are deduced from this analysis and experimental results are provided.

\section{MODELING OF THE DRIVE}

\section{A. Equivalent set of two 2-phase fictitious drives}

Under assumptions of no saturation and no reluctance effects, the vectorial approach developed in [16]-[19] allows to define the equivalence of a 5-phase wyeconnected machine Fig. 1) to a set of two fictitious independent drives, each one being composed of one fictitious machine and one fictitious inverter.

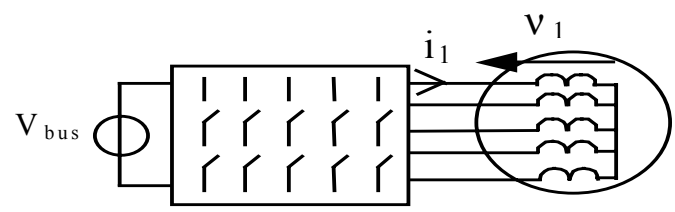

Fig. 1. Symbolic representation of the 5-leg PWM-VSI and $2 \mathrm{p}$ pole 5phase machine

The symmetry and the circularity of the stator inductance matrix are used to achieve the equivalence between the actual and the fictitious drives:

$$
\left[\mathrm{L}_{s}\right]=\left(\begin{array}{ccccc}
\mathrm{L} & \mathrm{M}_{1} & \mathrm{M}_{2} & \mathrm{M}_{2} & \mathrm{M}_{1} \\
\mathrm{M}_{1} & \mathrm{~L} & \mathrm{M}_{1} & \mathrm{M}_{2} & \mathrm{M}_{2} \\
\mathrm{M}_{2} & \mathrm{M}_{1} & \mathrm{~L} & \mathrm{M}_{1} & \mathrm{M}_{2} \\
\mathrm{M}_{2} & \mathrm{M}_{2} & \mathrm{M}_{1} & \mathrm{~L} & \mathrm{M}_{1}
\end{array}\right)
$$


$\left[\mathrm{L}_{\mathrm{s}}\right]$ matrix has three eigenvalues, named cyclic inductances, whose associated eigenspaces $\mathrm{G}_{\mathrm{g}}$ are orthogonal each others. The dimension of an eigenspace $G_{g}$ is equal to the multiplicity of its corresponding eigenvalue $L_{g}$. In the studied case, the multiplicity of two of them (noted $\mathrm{L}_{\mathrm{m}}$ and $\mathrm{L}_{\mathrm{s}}$ ) is of order two.

The orthogonality of the three eigenspaces $G_{m}, G_{g}$ and $G_{0}$ implies that three independent flux of energy can be found. To prove this assertion, an euclidian space with the usual canonic dot product is associated with the 5phase machine. This space is provided with an orthonormal base $\left\{\overrightarrow{x_{1}}, \overrightarrow{x_{2}}, \overrightarrow{x_{3}}, \overrightarrow{x_{4}}, \overrightarrow{x_{5}}\right\}$. In this natural base, voltage and current vectors are defined:

- $\vec{v}=v_{1} \overrightarrow{x_{1}}+v_{2} \overrightarrow{x_{2}}+\ldots+v_{5} \overrightarrow{x_{5}}$

- $\vec{i}=i_{1} \overrightarrow{x_{1}}+i_{2} \overrightarrow{x_{2}}+\ldots+i_{5} \overrightarrow{x_{5}}$

The coordinates of a vector in this base are the measurable values relative to each phase.

Using the dot product, the electric power is expressed by:

$$
p_{s}=\sum_{k=1}^{k=5} v_{k} i_{k}=\vec{v} \cdot \vec{i}
$$

Then, every vector is split into the sum of three vectors, each one belonging to an eigenspace, $\mathrm{G}_{\mathrm{m}}, \mathrm{G}_{\mathrm{s}}$ and $\mathrm{G}_{0}$ :

$$
\vec{y}=\overrightarrow{y_{m}}+\overrightarrow{y_{s}}+\overrightarrow{y_{0}}
$$

As the eigenspaces are orthogonal, the electric power is also the sum of three powers, associated each one with an eigenspace:

$$
p_{s}=\vec{v} \cdot \vec{i}=\overrightarrow{v_{m}} \cdot \overrightarrow{i_{m}}+\overrightarrow{v_{s}} \cdot \overrightarrow{i_{s}}+\overrightarrow{v_{0}} \cdot \overrightarrow{i_{0}}
$$

The wye-connection of the machine implies that $\overrightarrow{i_{0}}=\overrightarrow{0}$

Continuing the same energetic approach, it is easy to express the torque of the 5-phase machine as the sum of two torques $T_{m}$ and $T_{s}$ associated respectively to the eigenspaces $\mathrm{G}_{\mathrm{m}}$ and $\mathrm{G}_{\mathrm{s}}$ :

$$
T=T_{m}+T_{s}
$$

Each torque $T_{m}$ and $T_{s}$ is expressed as the following dot product:

$$
T_{m}=\frac{d \overrightarrow{\phi_{s r m}}}{d \theta} \cdot \overrightarrow{i_{m}} \text { and } T_{s}=\frac{d \overrightarrow{\phi_{s r s}}}{d \theta} \cdot \overrightarrow{i_{s}}
$$

with

- $\theta$, the mechanical angular position;

- $\overrightarrow{\phi_{s r}}$, the flux vector whose coordinate $\phi_{s r k}$ is the flux through the phase $k$ exclusively produced by the permanent magnets.

Moreover, as the control of the 5-leg VSI is achieved with a 2-level PWM, only average values of voltages are assumed to be imposed by the VSI. Using the same transformation as with the machine, the VSI is decomposed into two fictitious VSI. To get a characterization of each fictitious VSI it is sufficient to project the $2^{5}$ characteristic vectors of the 5-leg VSI onto the two eigenspaces $\mathrm{G}_{\mathrm{m}}$ and $\mathrm{G}_{\mathrm{s}}$. Two polyhedrons are obtained (Fig. 2 and Fig. 3).

Consequently there are two 2-phase machines represented in Fig. 4 by MM, the Main Machine and by $\mathrm{SM}$, the Secondary Machine. The MM (resp. SM) is characterized by its back-EMF $\overrightarrow{\mathrm{e}_{\mathrm{m}}}$ (resp. $\overrightarrow{\mathrm{e}_{\mathrm{s}}}$ ), its cyclic inductance $\mathrm{L}_{\mathrm{m}}\left(\right.$ resp. $\mathrm{L}_{\mathrm{s}}$ ) and its torque $\mathrm{T}_{\mathrm{m}}$ (resp. $\mathrm{T}_{\mathrm{s}}$ ). These two drives are mechanically coupled: they have the same mechanical angular velocity $\Omega$. They are supplied each one by a VSI, these two VSI being electrically coupled by a mathematical transformation.

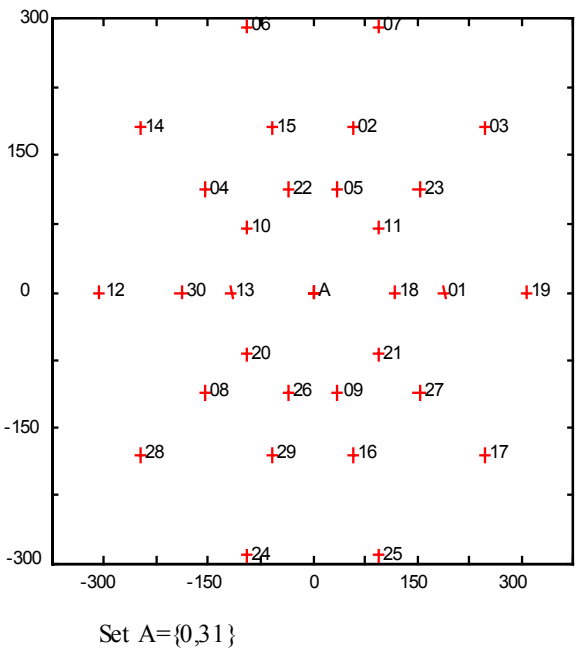

Fig. 2 Space Vector Representation of to the VSI which supplies MM

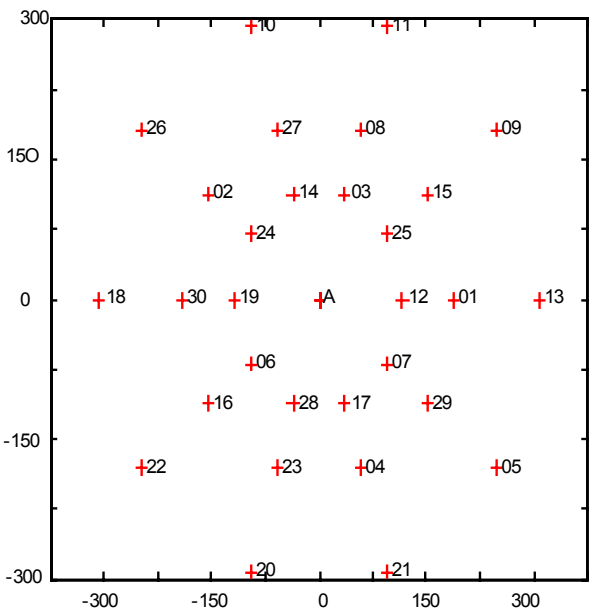

Fig. 3: Space Vector Representation of to the VSI which supplies SM

\section{B. Harmonic analysis of fictitious drives}

It is now interesting to characterize these fictitious machines to be able to control and supply them correctly. The expression (8) shows that the torque $T_{m}$ and $T_{s}$ are the dot product of the vectorial projections of two vectors. The first one is only depending on the design of the machine, the second one is imposed by the power supply.

As $d \overrightarrow{\phi_{s r}} / d \theta$ is a $2 \pi / p$ periodic function, it can be expanded into a Fourier series and consequently expressed as a sum of vectors associated with space harmonic order number $k$. Properties of symmetry, due to the regular manufacturing assumption, involve, as usual, the cancellation of cosine terms and of even sine terms. 


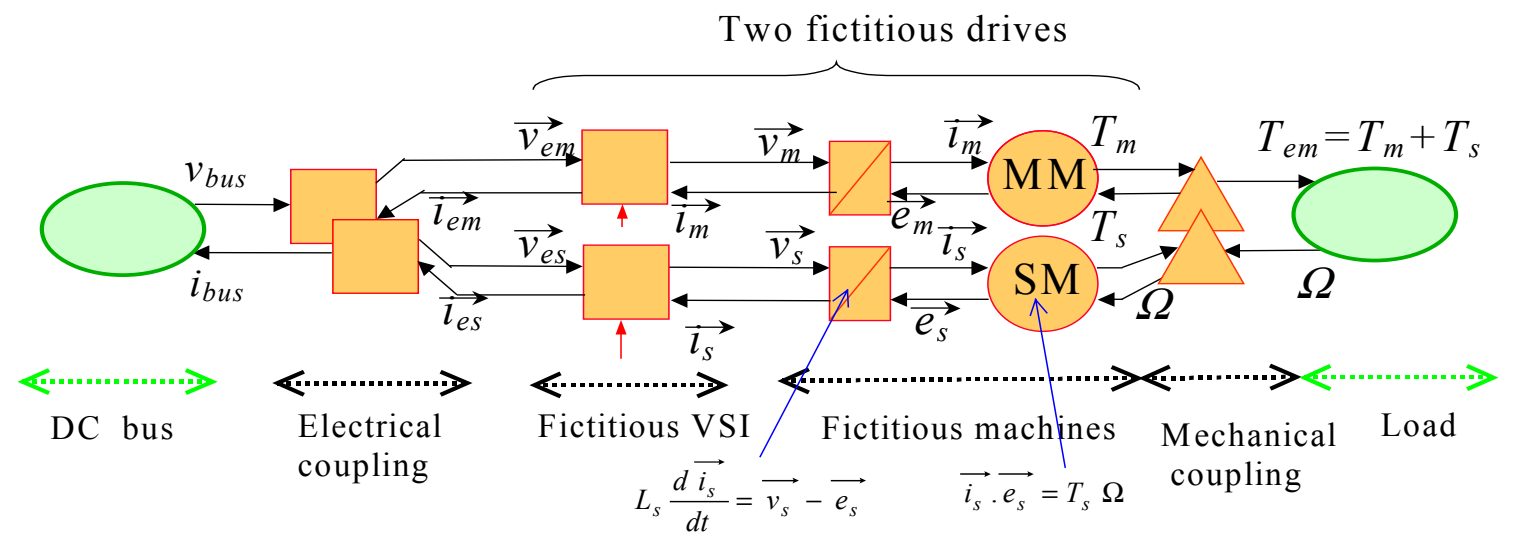

Fig. 4: Multi-machine Multi-Converter Representation of BLDC machine

Moreover, when a vector linked to a the space harmonic number $\mathrm{k}$ is projected onto an eigenspace the result depends on $\mathrm{k}$. According to the considered eigenspace associated with the fictitious studied machine, the null terms of the Fourier series are not the same. There is a distribution of the different space harmonics between the eigenspaces.

This particularity is verified for every vector which has the same mathematical properties as $d \overrightarrow{\phi_{s r}} / d \theta$. Thus, it is possible to associate to each fictitious machine a characteristic family of time or space harmonics:

- the Main Machine (MM) is associated with odd harmonics of $5 h \pm 1$ order: $1,9,11,19, \ldots$

- the Secondary Machine (SM) is associated with odd harmonics of $5 h \pm 2$ order: $3,7,13,17, \ldots$

- the $\mathrm{G}_{0}$ eigenspace is associated with odd harmonics of $5 h$.

In TABLE $\mathrm{I}$ is given harmonic decomposition of experimental back EMF Fig. 5).

TABLE I

HARMONIC DECOMPOSITION OF BACK-ELECTROMOTIVE OF ONE PHASE

\begin{tabular}{|c|c|c|c|c|c|}
\hline $\begin{array}{c}\text { Order of } \\
\text { harmonic }\end{array}$ & 1 & 3 & 5 & 7 & 9 \\
\hline $\begin{array}{c}\text { Relative RMS } \\
\text { amplitude }\end{array}$ & $\mathrm{E}_{1}=100 \%$ & $\mathrm{E}_{3}=29 \%$ & $\mathrm{E}_{5}=12,4 \%$ & $\mathrm{E}_{7}=5,1 \%$ & $\mathrm{E}_{9}=1,7 \%$ \\
\hline
\end{tabular}

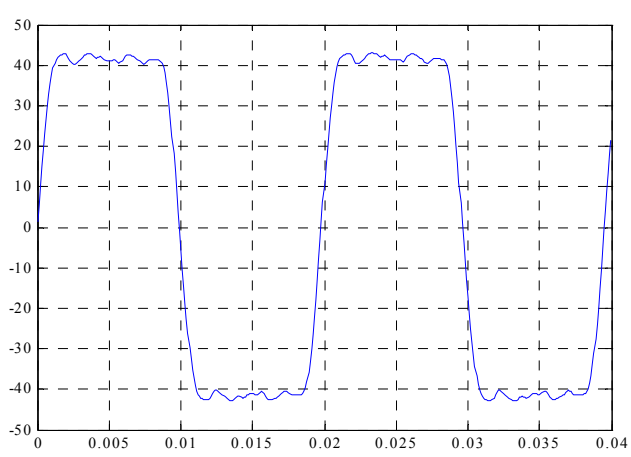

Fig. 5. Back-EMF of the machine

One can remark that the MM is almost a machine with a sinusoidal back-EMF since the $9^{\text {th }}$ represents only $1,7 \%$ of the first harmonic. For the SM the $7^{\text {th }}$ harmonic of
back-EMF, which is only $5,1 \%$ of the fundamental, represents $18 \%$ of the $3^{\text {rd }}$ harmonic. Consequently, the back-EMF of SM can not be considered sinusoidal because it is composed of $3^{\text {rd }}$ and $7^{\text {th }}$ harmonics.

\section{DEDUCED CONTROL OF EXPERIMENTAL SET UP}

Using causal EMR formalism (see Appendix on EMR formalism), the control structure is easily deduced by systematic inversion (Fig. 7). Thanks to this structure it appears clearly that a choice must be done to define the two references $T_{m-r e f}$ and $T_{s-r e f}$ from a torque reference $T_{e m-r e f}$. This is due to the mechanical coupling expressed by equation (7). This kind of choice is common in MultiMachine Multi-Converter systems and has been formalized in [20].

The control laws are then easy to implement because algorithms, already developed for 3-phase drives, can be directly used for each fictitious machine. Nevertheless, both fictitious machines have not the same reference frame. The first space harmonic of $\mathrm{MM}$ is the fundamental and implies that the angular velocity of the frame is $\mathrm{p} \Omega$. The first harmonic of $\mathrm{SM}$ is the $3^{\text {rd }}$ space harmonic and implies that the angular velocity of the frame is $3 \mathrm{p} \Omega$. A more usual synopsis of the control is presented in Fig. 8.

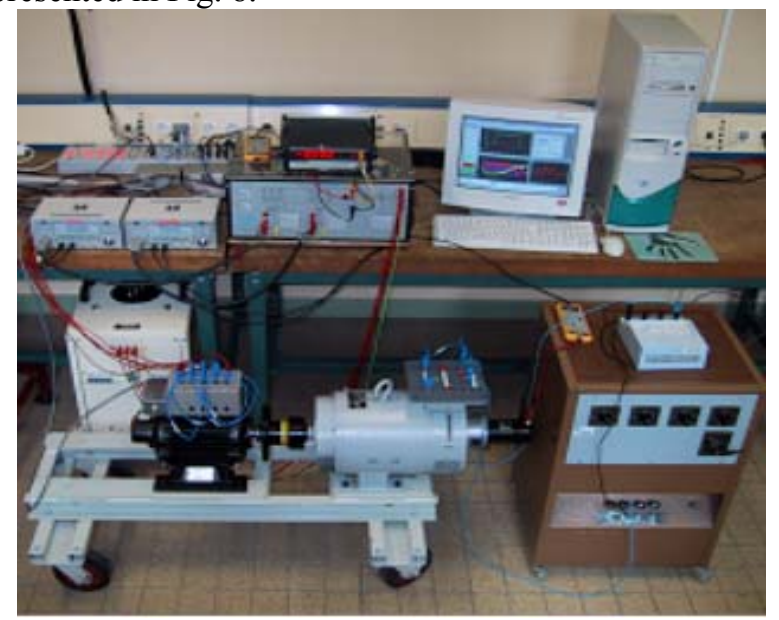

Fig. 6. experimental bench 
To exhibit easily at first the sensitivity of the $7^{\text {th }}$ space harmonic of back-EMF, the adopted strategy consists in using only the MM: $T_{m \text {-ref }}=T_{\text {em-ref }} ; T_{s-r e f}=0$. As the most important harmonics in the SM are the $3^{\text {rd }}$ and $7^{\text {th }}$ ones, the choice of $T_{\text {s-ref }}=0$ induces that the $3^{\text {rd }}$ time harmonic current must be equal to zero. Then the $7^{\text {th }}$ time harmonic is almost the only one in the SM as it appears in (Fig. 12, Fig. 14).

\section{A. Analysis of $7^{\text {th }}$ harmonic back-EMF effect}

The $7^{\text {th }}$ harmonic of back-EMF induces currents in the SM.

$i_{1-7}$, the RMS magnitude of these currents, is estimated by the following formula: $i_{1-7}=\frac{E_{7}}{\sqrt{R_{s}^{2}+\left(7 \Omega L_{s}\right)^{2}}}=1 \mathrm{~A}$. As the inductance $L_{s}$ of the $\mathrm{SM}$ is much more smaller than

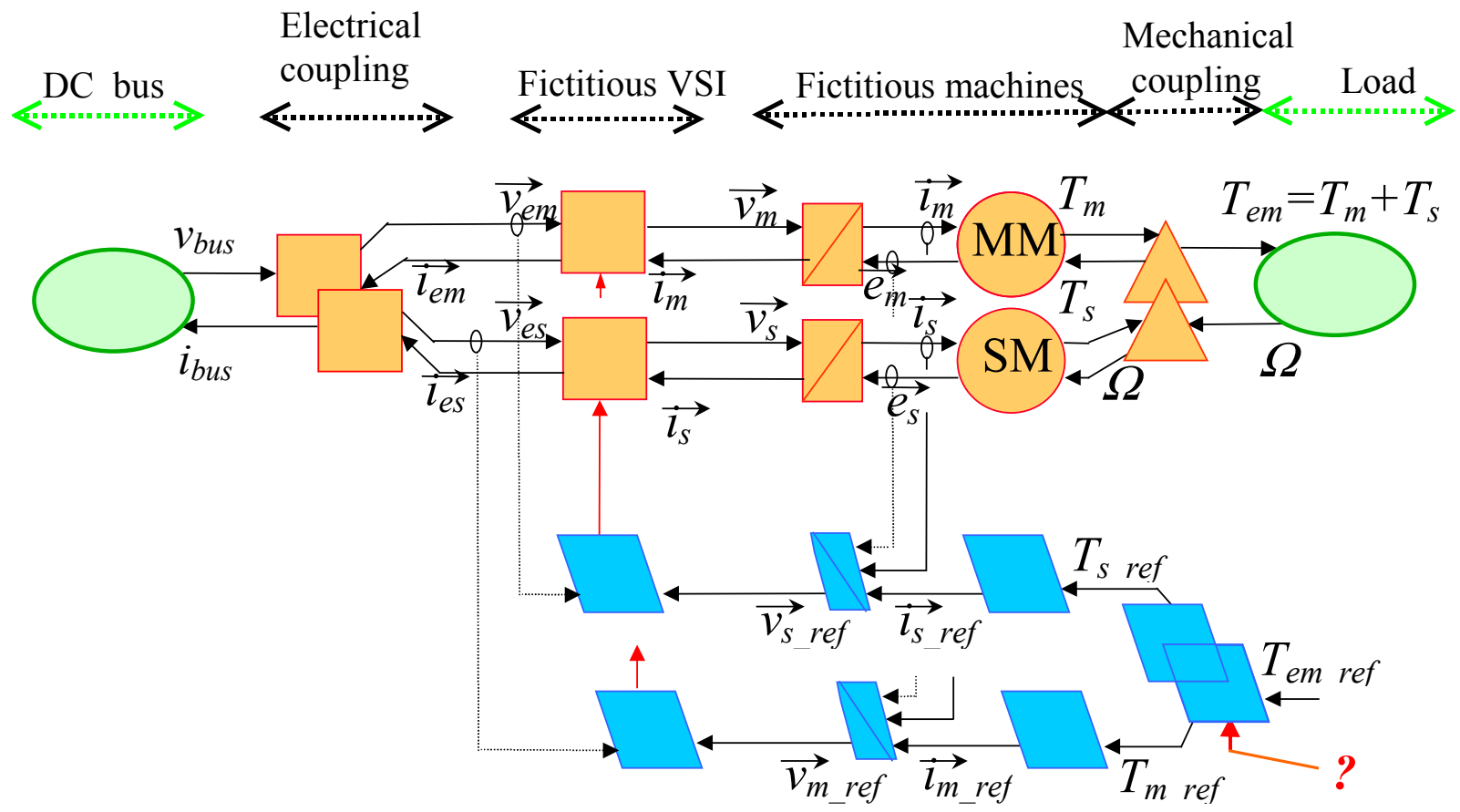

Fig. 7: Control structure of the 5-phase BLCD deduced from EMR

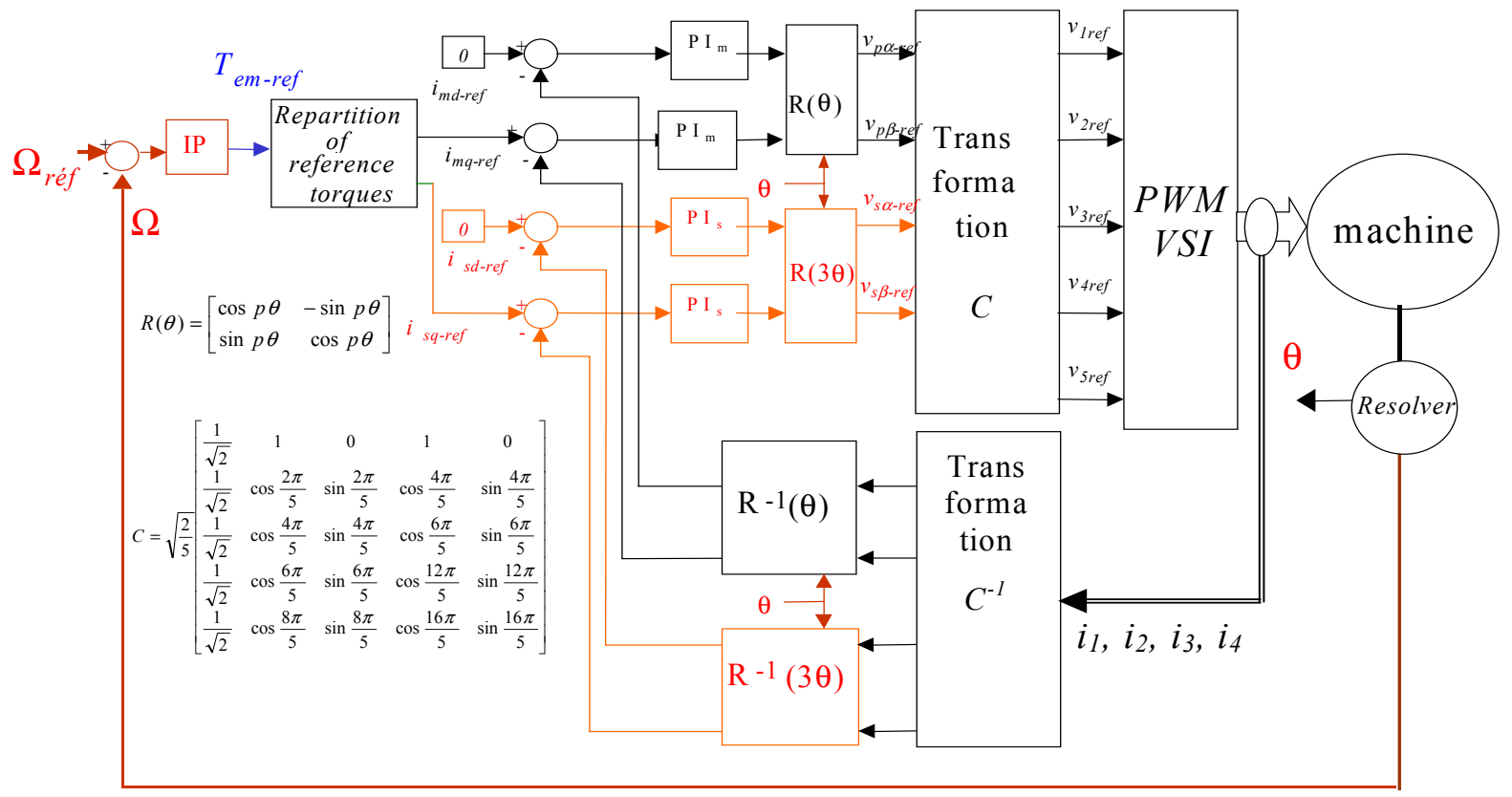

Fig. 8. Synopsis of control 
the inductance $L_{m}$ of the MM, this explains that even if $E_{7}$ is equal to $5,1 \%$ of $E_{1}$ then $i_{1-7}$ represents $29 \%$ of $i_{1-1}$ (Fig. 12).

\section{B. Compensation of $7^{\text {th }}$ harmonic back-EMF effect}

A compensation of this back-EMF in the SM has been implemented: Fig. 11, Fig. 13 and Fig. 15 show improvements of the control. Fig. 9 gives more global results of the control.

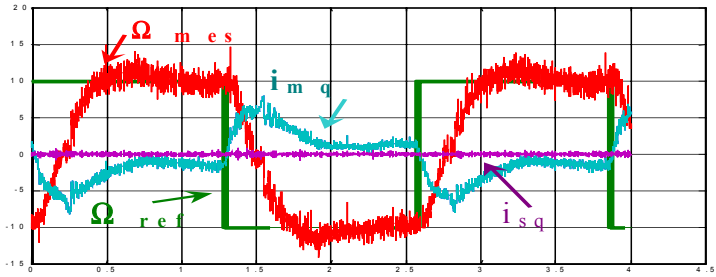

Fig. 9. Experimental active currents in $\mathrm{MM}$ and $\mathrm{SM}$ with compensation of $7^{\text {th }}$ harmonic of back-EMF and $\mathrm{T}_{\text {es-ref }}=0$

\section{Increasing torque using both fictitious machines}

As the back-EMF of SM is not equal to zero, it is possible to increase the torque with a same modulus of

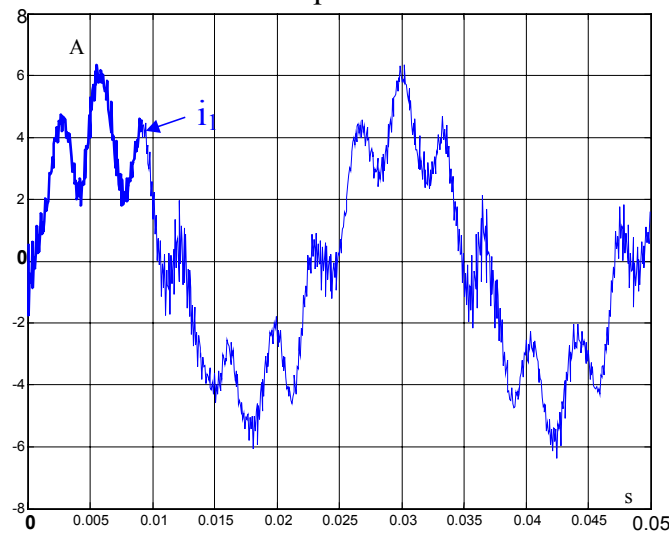

Fig. 10: Experimental $i_{1}$ current in phase $n^{\circ} 1$ at $1000 \mathrm{rpm}$ without compensation of $7^{\text {th }}$ harmonic of back-EMF

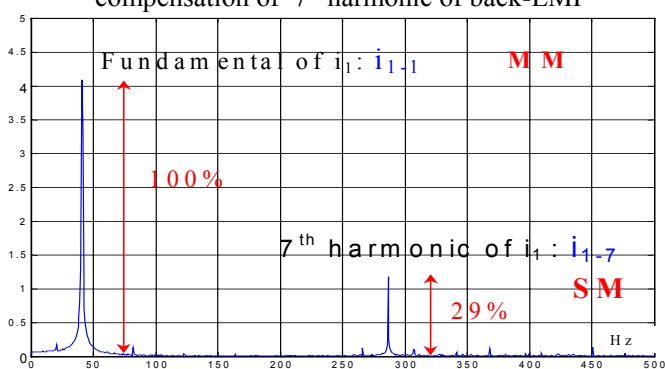

Fig. 12: Spectrum of experimental current $i_{1}$ at $1000 \mathrm{rpm}$ without compensation of $7^{\text {th }}$ harmonic of EMF
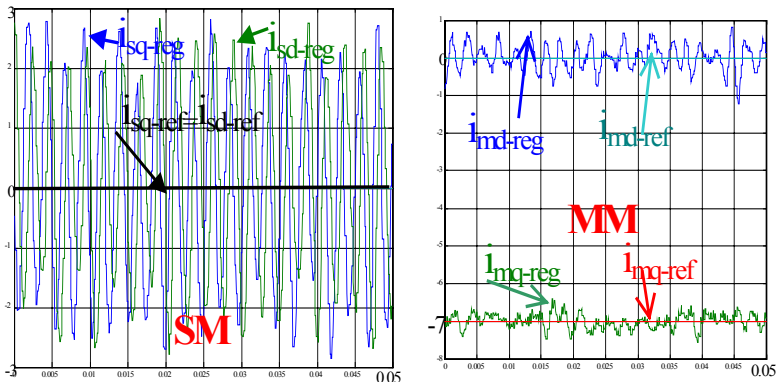

Fig. 14: Currents in the two fictitious 2-phase machines 'MM' and 'SM' without compensation of $7^{\text {th }}$ harmonic of back-EMF $\vec{i}$. Considering that $\mathrm{T}_{\mathrm{em}}$ is the dot product of $d \overrightarrow{\phi_{s r}} / d \theta$ by $\vec{i}$, the instantaneous value of $\mathrm{T}_{\mathrm{em}}$ is maximum if $d \overrightarrow{\phi_{s r}} / d \theta$ and $\vec{i}$ are collinear vectors. Taking into account only the $1^{\text {st }}$ and the $3^{\text {rd }}$ harmonics, the repartition between $T_{m-r e f}$ and $T_{s-r e f}$ is then $29 \%$ (the same repartition as between $\mathrm{E}_{1}$ and $\mathrm{E}_{3}$, TABLE I).

\section{CONCLUSION}

An original modeling of a 5-phase machine allows to exhibit particularity of this kind of machine compared with 3-phase one. The sensitivity of the 5-phase drive to the $7^{\text {th }}$ space harmonic is easily explained. Moreover, the EMR modeling allows to find how to compensate the high magnitude parasitic currents induced by the $7^{\text {th }}$ harmonic of back-EMF. Experimental results show then improvements. Finally, a control where the two fictitious drives are simultaneously supplied is presented. The algorithms are the same as those already used in 3-phase machines.

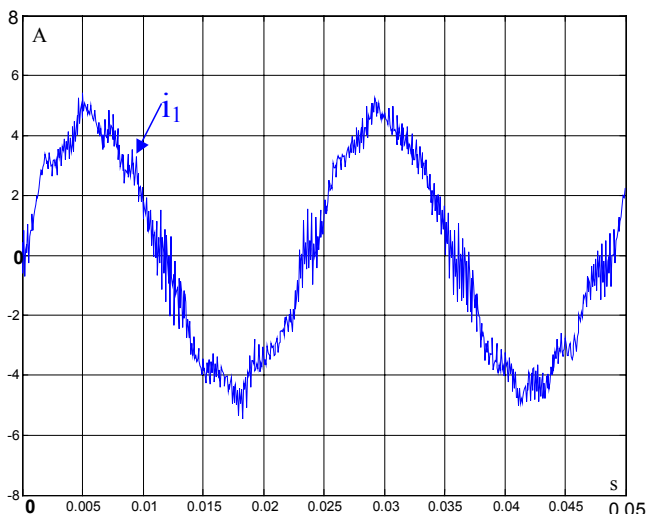

Fig. 11: Experimental $i_{1}$ current in phase $n^{\circ} 1$ at $1000 \mathrm{rpm}$ with compensation of $7^{\text {th }}$ harmonic of back-EMF

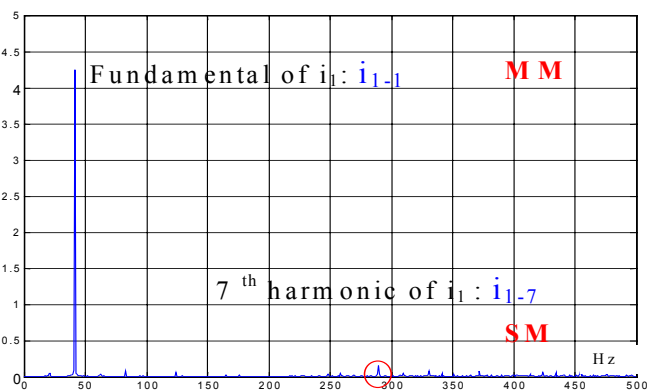

Fig. 13: Spectrum of experimental current $i_{1}$ at $1000 \mathrm{rpm}$ with compensation of $7^{\text {th }}$ harmonic of EMF
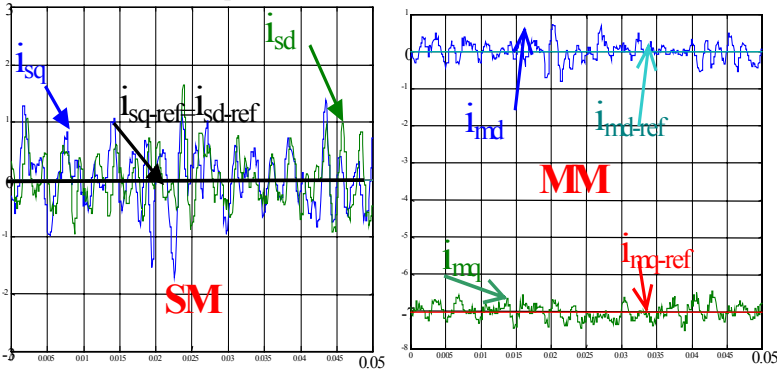

Fig. 15: Currents in the two fictitious 2-phase machines 'MM' and 'SM' with compensation of $7^{\text {th }}$ harmonic of back-EMF 


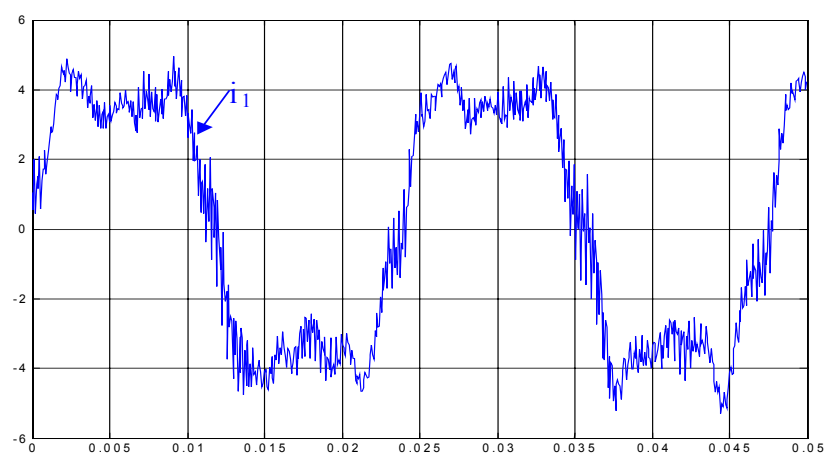

Fig. 16: Experimental $i_{1}$ current in phase $n^{\circ} 1$ at $1000 \mathrm{rpm}$ with compensation of $7^{\text {th }}$ harmonic of back-EMF and the repartition between MM and SM $\mathrm{i}_{\mathrm{sq}-\mathrm{ref}}=(29 \%) \mathrm{i}_{\mathrm{mq}-\text {-ref- }}$.
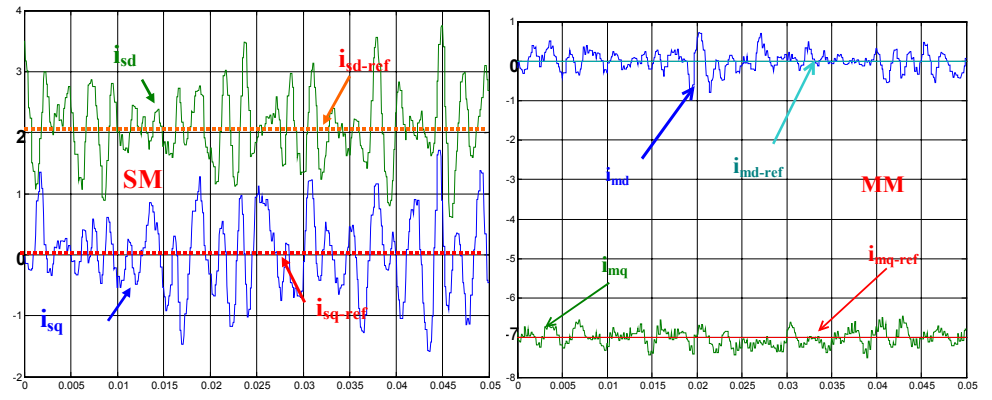

Fig. 18: Currents in the two fictitious 2-phase machines 'MM' and 'SM' with compensation of $7^{\text {th }}$ harmonic of back-EMF

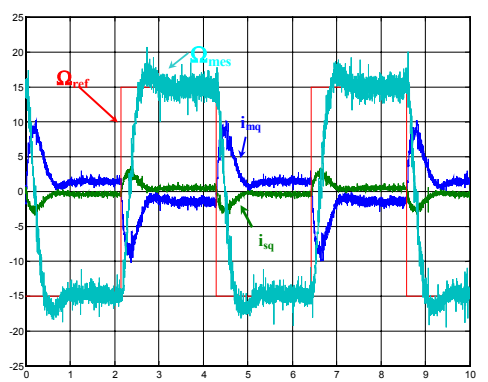

Fig. 17: Experimental active currents in MM and SM with compensation of $7^{\text {th }}$ harmonic of back-EMF and $\mathrm{T}_{\text {es-ref }}=(29 \%) \mathrm{T}_{\mathrm{ms}-\mathrm{ref}}$

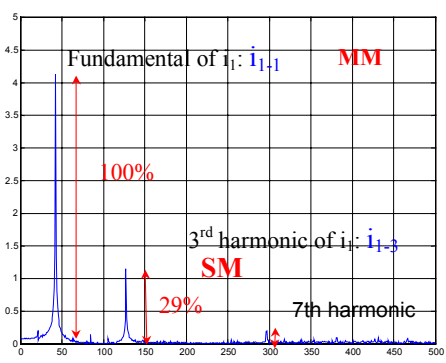

Fig. 19: Spectrum of Fig. 16 experimental current $i_{1}$

\section{APPENDIX ON EMR FORMALISM}

The Energetic Macroscopic Representation (EMR) [22] is a synthetic graphical tool based on the principle of action and reaction between elements [21]. It leads to a synthetic description of an overall conversion system between two sources (oval green pictogram). It uses elements which accumulate energy (rectangular orange pictogram with an oblique bar) and elements which convert energy without energy or storage (orange square for electrical conversion, circle for electromagnetic conversion and triangle for mechanical conversion).

From the EMR of an electromechanical conversion, one can deduce a control structure, which is composed of the maximum of control operations and measurements [22].

This modeling has successfully been applied to electric vehicles, high-speed railway traction systems, wind energy conversion systems, ship propulsion with doublestar induction machines.

EMR of an energy conversion - An energy conversion between two sources $S_{1}$ and $S_{2}$ is represented by an association of power components (Fig. 20): a conversion element and two accumulation elements. All of them are connected by exchange vectors.

A source element produces a state variable (output). The source is either a generator or receptor. It is disturbed by the reaction of the connected element (input), for example, the absorbed current for a voltage grid.

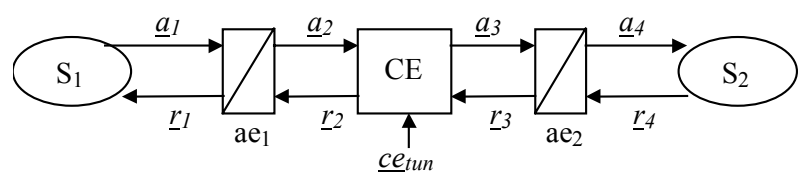

Fig. 20: EMR between two sources

A conversion element yields an energy conversion without energy loss nor storage. Its tuning is ensured by an input vector $e c_{t u n}$ which consumes less power than the transferred one. In some case, there is no tuning input and the conversion transfer is realized with a fixed rate.

An accumulation element connects an energy source to a conversion element, thanks to an energy storage, which induces at least one state variable. Such element has no tuning input.

The exchange vectors yield the energy to be transferred between the connected components according to the principle of action and reaction. On Fig. 20, the source $S_{1}$ is chosen arbitrarily as the upstream source. It produces an action which is transmitted then to the downstream source $\mathrm{S}_{2}$ which answers by a reaction. So, one defines a chain of action variables $\left(\underline{a}_{i}\right)$ and a chain of reaction variables $\left(\underline{r}_{i}\right)$. These variables can be scalar or vector. The two connected components are dual each other: if the action is potential, the reaction is kinetic.

Extension to Multi-machine Multi-converter Systems (MMS) - A MMS is composed of several monomachine mono-converter systems, which share one or 
more power devices. Thus, it yields energy distribution between electric and mechanical sources through coupled conversion chains, which can yield interactions (disturbances) between power structures. The MMS have to enable best power repartition with lower cost equipment.

The energy distribution is obtained by specific conversion structures [19]. These power components are common to several conversion chains. They are called coupling structures. A coupling conversion structure links an upstream device with many downstream one's, or vice versa. Such structures are drawn by forms with intersections (Fig. 21).

The electric coupling is associated with electric converters. It corresponds to a common electric device of several converters (power switch, capacitor...). It leads to a common electric variable (voltage, current...).

The magnetic coupling is associated with electric machines.

The mechanical coupling is associated with mechanical converters.

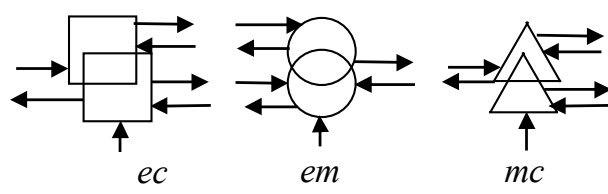

Fig. 21: Examples of coupling devices

\section{ACKNOWLEDGMENT}

This work is part of the project 'Futurelec2' within the 'Centre National de Recherche Technologique (CNRT) of Lille'. The support of the CNRT is kindly acknowledged.

\section{REFERENCES}

[1] T.M. Jahns "Improved reliability in solid state ac drives by means of multiple independent phase-drive units", IEEE Transactions on Industry Applications, vol. IA-16, May-June 1980, pp. 321-331.

[2] H.A. Toliyat, "Analysis and Simulation of Five-Phase VariableSpeed Induction Motor Drives Under Asymmetrical Connections", IEEE Transactions on Power Electronics, vol. 13 no 4, July 1998, pp. 748-756.

[3] R. Bhatia, H. Krattiger, A. Bonanini, D. Schafer, J.T. Inge, G.H. Sydnor, "Adjustable Speed Drive With A Single 100-MW Synchronous Motor", ABB Review, Issue no 6, 1998, pp.14-20.

[4] H. Godfroi, P. Bosc , "Large variable speed drives using synchronous motors and frequency converters", Alstom Review, no $6,1986$.

[5] S.D. Sudhoff, "Analysis and average-value modelling of dual linecommutated converter 6-phase synchronous machine systems", IEEE Transactions on Energy Conversion, vol. 8, no. 3, September 1993, pp. 411-417

[6] S. Siala S., E. Guette, J. L. Pouliquen, “Multi-inverter PWM control: a new generation drives for cruise ship electric propulsion", European Power Electronics Conference (EPE'2003), September 1993, Toulouse (France), CD-ROM.

[7] H. Xu, H. A. Toliyat, L. J. Petersen, "Five-Phase Induction Motor Drives With DSP-Based Control System", IEEE Transactions on Power Electronics, vol. 17 no 4, July 2002, pp. 524-533.

[8] J. Cros, C. Paynot, J. Figueroa, P. Viarouge, "Multi-Star PM brushless DC motor for traction applications", European Power Electronics Conference (EPE'2003), Toulouse (France), September 2003, CD-ROM.
[9] D.W. Novotny, T.A. Lipo, Vector Control and dynamics of $A C$ drives, New York, Oxford University Press Inc, 2000.

[10] Y. Zhao, T. A. Lipo, " Space Vector PWM Control of Dual Three-Phase Induction Machine Using Space Vector Decomposition ", IEEE Transactions on Industry Applications, vol. 31 no.5, September/October 1995, pp. 1100-1109.

[11] R. O. C. Lyra, T.A. Lipo, “ Torque Density Improvement in a SixPhase Induction Motor With Third Harmonic Current Injection", IEEE-IAS annual meeting 2001, September/October 2001, Chicago (USA), CD-ROM.

[12] E. Levi, M. Jones, S.N. Vukosavic, H.A. Toliyat, "A Five-Phase Two-Machine Vector Controlled Induction Motor Drive Supplied from a Single Inverter", European Power Electronics Conference (EPE2003), Toulouse (France), September 2003, CD-ROM.

[13] R. Shi R., H. A. Toliyat, A. El-Antably, "Field Oriented Control of Five-phase Synchronous Reluctance Motor Drive with Flexible 3rd Harmonic Current Injection for High Specific Torque ", IEEE-IAS annual meeting 2001, September/October 2001, Chicago (USA), CD-ROM.

[14] J. Figueroa, J. Cros, P. Viarouge, "Current Control Strategies for Seven Phase Brushless DC Motors", International Congress on Electrical Machines (ICEM'02), August 2002, Brugges (Belgium), CD-ROM.

[15] G. Simões, P. Vieira, "A High-Torque Low-Speed Multiphase Brushless Machine-A Perspective Application", IEEE Transactions on Industrial Electronics, vol. 49, no. 5, October 2002, pp. 1154-1164.

[16] E. Semail, A. Bouscayrol, J.P. Hautier, "Vectorial formalism for analysis and design of polyphase synchronous machines", EPJ AP (European Physical Journal-Applied Physics), vol. 22 no 3, June 2003, pp. 207-220.

[17] E. Semail, "Tools and studying method of polyphase electrical systems. Generalization of the space vector theory", Ph.D. thesis, University of Sciences and Technologies of Lille, June 2000 (text in French).

[18] X. Kestelyn, "Vectorial Multi-machine Modeling for the control of Multi-phase drives ", Ph.D. thesis, University of Sciences and Technologies of Lille, December 2003 (text in French).

[19] X. Kestelyn, E. Semail, JP. Hautier, "Vectorial Multi-machine modeling for a five-phase machine", International Congress on Electrical Machines (ICEM'02), August 2002, Brugges (Belgium), CD-ROM.

[20] A. Bouscayrol, B. Davat, B. de Fornel, B. François, J. P. Hautier, F. Meibody-Tabar, E. Monmasson, M. Pietrzak-David, H. Razik, E. Semail, M. F. Benkhoris, "Control Structures for Multimachine Multi-converter Systems with upstream coupling", Mathematics and Computers in Simulation, vol. 63, no3-5, November 2003, pp. 261-270 (common paper of GE44, GREEN, L2EP, LEEI and SATIE according to the MMS project of GDRME2MS).

[21] A. Bouscayrol , B. Davat, B. De Fornel, B.François, J. P. Hautier, F. Meibody-Tabar, M. Pietrzak-David, "Multi-machine multiconverter systems: applications to electromechanical drives", EPJ Applied Physics, Vol. 10, no. 2, May 2000, pp131-147 (common paper of GREEN, L2EP and LEEI, according to the MMS project of GDR-SDSE).

[22] A. Bouscayrol, X. Guillaud, J. P. Hautier, Ph. Delarue, "Macromodeling of electromechanical conversion; application to the electrical machine control", (text in French), RIGE, Vol. 3, no.2, June 2000, pp 257-282. 